\title{
Assessment of Anti-TB Drug Nonadherence and Associated Factors among TB Patients Attending TB Clinics in Arba Minch Governmental Health Institutions, Southern Ethiopia
}

\author{
Addisu Alemayehu Gube $\mathbb{D}^{1},{ }^{1}$ Megbaru Debalkie $\mathbb{D}^{2},{ }^{2}$ Kalid Seid $\mathbb{D},{ }^{2}$ Kiberalem Bisete $\mathbb{D}^{2},{ }^{2}$ \\ Asfaw Mengesha $\mathbb{D}^{\mathbb{D}},{ }^{2}$ Abubeker Zeynu $\mathbb{D}^{\mathrm{D}},{ }^{2}$ Freselam Shimelis $\mathbb{D}^{2},{ }^{2}$ and Feleke Gebremeskel ${ }^{1}$ \\ ${ }^{1}$ Department of Public Health, College of Medicine and Health Sciences, Arba Minch University, P.O. Box 21, Arba Minch, Ethiopia \\ ${ }^{2}$ Department of Nursing, College of Medicine and Health Sciences, Arba Minch University, P.O. Box 21, Arba Minch, Ethiopia
}

Correspondence should be addressed to Addisu Alemayehu Gube; addis166@gmail.com

Received 8 July 2017; Revised 8 September 2017; Accepted 28 November 2017; Published 18 February 2018

Academic Editor: Vincent Jarlier

Copyright (c) 2018 Addisu Alemayehu Gube et al. This is an open access article distributed under the Creative Commons Attribution License, which permits unrestricted use, distribution, and reproduction in any medium, provided the original work is properly cited.

Background. Tuberculosis (TB) is an infectious disease caused by the bacillus Mycobacterium tuberculosis. Nonadherence to anti$\mathrm{TB}$ treatment may result in the emergence of multidrug-resistant TB, prolonged infectiousness, and poor tuberculosis treatment outcomes. Ethiopia is one of the seven countries that reported lower rates of treatment success (84\%). This study assessed antiTB drug nonadherence and associated factors among TB patients in Arba Minch governmental health institutions. Methods. An institution based cross-sectional study design was conducted from April 15 to May 30, 2017. A systematic sampling technique was employed to select the study subjects. Data was collected using a semistructured questionnaire with Morisky Medication Adherence Scale-8 (MMAS-8) and was entered, cleaned, and analyzed in SPSS version 20. Results. The study included 271 TB patients with a response rate of $96.4 \%$; $58.3 \%$ were males and $64.9 \%$ were Gamo by ethnicity. The overall nonadherence was $67(24.7 \%)(\mathrm{CI}=$ 20.0-30.4). Nonadherence was high if the patients experienced side effects ( $\mathrm{AOR}=13.332 ; 95 \% \mathrm{CI}=2.282-77.905)$, were far from the health facility $(\mathrm{AOR}=21.830 ; 95 \% \mathrm{CI}=0.054-77.500)$, and experienced prolonged waiting time to get medical services $(\mathrm{AOR}=$ $14.260 ; 95 \% \mathrm{CI}=2.135-95.241)$. Conclusions. The proportion of TB patients that did not adhere to anti-TB drugs was high in Arba Minch governmental health institutions.

\section{Introduction}

Tuberculosis is an infectious disease caused by the bacillus Mycobacterium tuberculosis. It typically affects the lungs (pulmonary TB) but can also affect other sites (extrapulmonary TB). The disease is spread when people sick with pulmonary TB expel bacteria to the air, for example, by coughing. Overall, a relatively small proportion $(5-15 \%)$ of the estimated 2-3 billion people infected with Mycobacterium tuberculosis will develop TB disease during their lifetime [1]. The prevalence of TB among close contacts of infectious patients can be about 2.5 times higher than in the general population [2]. If TB is detected early and fully treated, people with disease quickly become noninfectious and are eventually cured [3].
The WHO, in its global plan to stop TB, reports that poor treatment has resulted in the evolution of Mycobacterium tuberculosis strains that do not respond to treatment with the standard first-line combination of anti-TB medicines, resulting in the emergence of multidrug-resistant $\mathrm{TB}$ in almost every country of the world [4]. One of the greatest dilemmas and challenges facing most TB programs is a patient that does not complete TB treatment for one reason or another [5].

Poor adherence to treatment of chronic diseases including TB is a worldwide problem of striking magnitude [6]. However, patients with TB are expected to have adherence levels greater than $90 \%$ in order to facilitate cure. Failure of cure increases the risk of development of drug-resistant strains and spread of TB in the community, and this in turn 
increases morbidity and mortality [7, 8]. TB in 2015 was one of the top 10 causes of death worldwide. The best estimates are that there were 1.4 million TB deaths in 2015 and an additional 0.4 million deaths resulting from TB disease among HIVpositive people [1]. According to recent estimates, Ethiopia stands 7 th in the list of high TB burden countries. In Ethiopia, TB is the leading cause of morbidity, the third cause of hospital admissions, and the second cause of death. The estimated TB incidence of Ethiopia was 261/100,000 inhabitants in 2011. The lifetime risk of developing TB in Ethiopia is estimated to be $50-60 \%$ for $\mathrm{HIV}$-infected people and only $10 \%$ for HIVnegative counterparts $[9,10]$. In many countries, globally, the adoption of Directly Observed Treatment (DOT) has been associated with reduced rate of treatment failure, relapse, and drug resistance. However, its impact on reducing TB incidence has been limited by noncompliance to DOT, which occurs when patients do not turn up for treatment at the health facility or community DOT point [11].

Despite the implementation of an internationally recommended strategy (DOT) in almost all parts of WHO regions and many national and international efforts exerted against TB prevention and control, still the patients fail to complete their treatment to be declared "cured" or "completed the treatment" [12-14]. Current WHO reports show that a considerable number of TB cases failed after several treatments; many relapsed after completion of the treatment, many had to undergo retreatment after completion of treatment, and many developed MDR-TB among retreatment cases (20\%) throughout the world [15]. For this, most probably, treatment nonadherence and loss to followup are the main responsible factors [16]. Nonadherence to anti-TB treatment may result in the emergence of multidrug-resistant TB (MDR-TB), prolonged infectiousness, and poor TB treatment outcomes $[17,18]$. In sub-Saharan Africa, there is a high rate of loss to followup of TB patients that ranged from $11.3 \%$ to $29.6 \%$ [19]. Ethiopia is one of the seven countries that reported lower rates of treatment success (84\%) [9].

In Ethiopia, even though $\mathrm{TB}$ drugs are given free of charge, TB continues to be a major health problem and cause of death. The Ethiopian national program for TB control recommends DOT as the main strategy for disease control, but its utilization differs due to local health institutions' capacities to guarantee patient supervision. Hence, this study will assess the level of nonadherence to anti-TB therapy and associated factors among TB patients in Arba Minch, Ethiopia.

\section{Methods and Materials}

2.1. Study Area and Period. The study was conducted in Arba Minch town, Gamo Gofa Zone SNNPR, Ethiopia. The town is located at $505 \mathrm{~km}$ from Addis Ababa and $275 \mathrm{~km}$ from Hawassa, capital city of Southern Ethiopia. The town is $30^{\circ}$ $56^{\prime}$ north and $37^{\circ} 44^{\prime}$ west, and it is located to the west of Lake Abaya. It covers $514 \mathrm{~km}^{2}$ and is generally located at the altitude of 1200 through 1400 meters above sea level. Based on the 2007 Ethiopian national population and housing census, the population of the town is projected to be about 86,405 . The town has three public facilities: two health centers and one general hospital. Arba Minch General Hospital was established and started its full function in 1961 EC (Ethiopian Calendar). The hospital and the health centers are now providing several health services including $\mathrm{TB}$ treatment program for the community. The study was conducted from April 15 to May 30, 2017.

2.2. Study Population. The study population included all TB patients on anti-TB medication at least for a month at tuberculosis followup clinics in Arba Minch governmental health institutions.

2.3. Inclusion Criteria. All TB patients that were at least 15 years of age, regardless of the site or the smear status of their $\mathrm{TB}$, and have taken anti-TB medication at least for a month were included.

2.4. Sample Size and Sampling Techniques. The sample size was calculated based on a single population proportion formula using the following assumptions: $P=21 \%$ [20], with $95 \%$ confidence level and 5\% level of precision. And by adding $10 \%$ for nonresponse rate, the final sample size was 281. In order to draw the sample, average flow of TB patients in each health institution per day was taken as a reference to estimate the client load. Based on the information, proportionate allocation to size was made in each institution. Therefore, 52\% (146) of the sample was drawn from Arba Minch General Hospital, 32\% (90) from Sikella Health Center, and the rest $(16 \%, 45)$ from Shecha Health Center. Since TB patients receive the same TB clinic service. Systematic random sampling was used, and by dividing the total 436 patients to 281 patients, every 2 nd TB patient was selected. The first study subject was determined randomly.

2.5. Data Collection Instrument and Procedures. Data was collected using a pretested and semistructured questionnaire. It was in English and was translated to Amharic and then back to English to check for consistency and completeness. Then, it was collected through a face-to-face exit interview.

2.6. Operational Definitions. Nonadherence to anti-TB drugs means an individual whose score $>2$ points in the Morisky Medication Adherence Scale-8.

MMAS-8 consists of eight items, with a scoring scheme of "yes" = 0 and "no" $=1$ for the first seven items, but for the last item, a five-point Likert scale response will be used with options of "never," "once in a while," "sometimes," "usually," and "always." In this Likert scale, values ranging from 0 to 1 were given at a specified interval of 0.25 with " 0 " given for "never" and " 1 " given for "always." The degree of adherence was determined according to the score resulting from the sum of all the correct answers to a maximum score of 8 . For the purpose of data analysis, the three original categories of adherence were recategorized into two. Accordingly, high and medium adherence were reassigned as adherent with a score of less than or equal to 2 and low adherence will be regarded as nonadherent with a score of greater than 2 . 
2.7. Data Processing and Analysis. After checking for completeness and consistency, data was entered into SPSS (IBM 20) for descriptive and inferential analysis. Binary logistic regression was used to determine the dependent variable on the basis of continuous and/or categorical independent variables, and factors with $P$ value $\leq 0.25$ in bivariate analysis were candidates for multivariate analysis and factors with $P<0.05$ in the final model were statistically significant. The degree of association between dependent and independent variables was assessed using AOR at 95\% CI.

2.8. Ethical Consideration. Ethical clearance was obtained from the ethical review committee of the College of Medicine and Health Sciences, Arba Minch University. A formal letter was given to each of the public health institutions in Arba Minch town. In addition, informed consent was obtained from study participants to confirm their willingness for participation after explaining the objective of the study. And the respondents were notified that they have the right to withdraw at any point of the interview.

\section{Results}

3.1. Sociodemographic Characteristics of the Study Participants. From 281 selected participants, 271 were involved in the study with a response rate of $96.4 \%$. Of these, 142 $(52.4 \%)$ were aged $25-34$, with a mean age of $32.19( \pm 11.291$ SD) years. Of 271, $158(58.3 \%)$ were males and $170(62.7 \%)$ were protestants. $190(70.1 \%)$ of the participants were married and $176(64.9 \%)$ were Gamo by ethnicity. $82(30.3 \%)$ of the study participants attended grades 7-12, 183 (67.5\%) were self-employed, and 169 (62.4\%) got more than 501 birr as a monthly income (Table 1).

3.2. Behavioral Risk Factors of Study Participants. 249 (91.9\%) of the study participants had no smoking habit and 227 (83.8\%) never drank alcohol before. 15 (5.5\%) of the study participants had no treatment supporter (Table 2).

3.3. Healthcare System Related Characteristics of the Study Participants. 150 (55.3\%) stated that their preferable TB clinic opening time was from 2:00 AM to 6:00 PM local time, and for $225(83.0 \%)$, the waiting time at the health facility was $<1$ hour. $56(20.7 \%)$ of the participants reported that it took them more than $5 \mathrm{kms}$ and 5 birr to reach the nearby TB clinic.

$44(16.2 \%)$ of the study participants stated that no one supervised them while taking their TB medication. 208 $(76.8 \%)$ reported that the health workers were friendly to them.

259 (95.6\%) participants had good knowledge about TB but $12(4.4 \%)$ participants did not know the symptoms of TB at all. $46(17.0 \%)$ of the participants reported that they stopped taking their anti-TB medication when they felt better. 249 (91.9\%) disclosed their illness to their relatives, and all those who did not disclose had fear of stigma and discrimination (Table 3).

3.4. Disease and Medicine Related Factors. 30 (11.1\%) of the TB patients reported some kind of anti-TB medication
TABLE 1: Sociodemographic characteristics of the TB patients that attended TB clinics at governmental health institutions of Arba Minch town, Southern Ethiopia, $2017(N=271)$.

\begin{tabular}{|c|c|c|}
\hline Variable & Frequency & Percent \\
\hline \multicolumn{3}{|l|}{ Age } \\
\hline $15-24$ & 65 & 24 \\
\hline $25-34$ & 142 & 52.4 \\
\hline $35-44$ & 30 & 11 \\
\hline$>=45$ & 34 & 12.6 \\
\hline \multicolumn{3}{|l|}{ Sex } \\
\hline Male & 158 & 58.3 \\
\hline Female & 113 & 41.7 \\
\hline \multicolumn{3}{|l|}{ Marital status } \\
\hline Married & 190 & 70.1 \\
\hline Single & 50 & 18.5 \\
\hline Divorced & 21 & 7.7 \\
\hline Widowed & 10 & 3.7 \\
\hline \multicolumn{3}{|l|}{ Religion } \\
\hline Protestant & 170 & 62.7 \\
\hline Orthodox & 90 & 33.2 \\
\hline Muslim & 11 & 4.1 \\
\hline \multicolumn{3}{|l|}{ Ethnicity } \\
\hline Gamo & 176 & 64.9 \\
\hline Wolaita & 80 & 29.5 \\
\hline Gofa & 15 & 5.5 \\
\hline \multicolumn{3}{|l|}{ Educational status } \\
\hline Cannot read and write & 25 & 9.2 \\
\hline Can read and write & 62 & 22.9 \\
\hline Grades 1-6 & 75 & 27.7 \\
\hline Grades 7-12 & 82 & 30.3 \\
\hline Diploma and above & 27 & 10.0 \\
\hline \multicolumn{3}{|l|}{ Occupational status } \\
\hline Employee & 57 & 21 \\
\hline Self-employed & 183 & 67.5 \\
\hline No job & 31 & 11.4 \\
\hline \multicolumn{3}{|l|}{ Monthly income } \\
\hline$<501$ birr & 102 & 37.6 \\
\hline$>=501$ birr & 169 & 62.4 \\
\hline
\end{tabular}

adverse effects: of these, 10 (33.4\%), 9 (30\%), 7 (23.3\%), and $4(13.3 \%)$ participants complained of minor adverse effects, that is, vomiting and diarrhea, numbness of feet and hands, headache and dizziness, and skin rash, respectively. 257 (94.8\%) of the participants reported that they felt better in less than 2 months' time after starting anti-TB medication.

$229(84.5 \%)$ of the TB patients were screened for HIV and $6(2.2 \%)$ of them were positive. $14(5.2 \%)$ of the TB patients have taken drugs other than anti-TB medication: of these, 6 (42.8\%) for HIV, 2 (14.3\%) for pneumonia, 1 (7.1\%) for STI, and $5(35.8 \%)$ for fungal diseases (Table 4$)$.

3.5. Prevalence of Nonadherence to Anti-TB Medication. The overall calculated nonadherence in this study was $67(24.7 \%)$ with a confidence interval (CI) of 20.0-30.4 (Figure 1). 
TABLE 2: Behavioral characteristics of the TB patients that attended TB clinics at governmental health institutions of Arba Minch town, Southern Ethiopia, $2017(N=271)$.

\begin{tabular}{lcc}
\hline Variable & Frequency & Percent \\
\hline Smoking & 22 & \\
Yes & 249 & 8.1 \\
No & & 91.9 \\
Alcohol & 44 & \\
Yes & 227 & 16.2 \\
No & & 83.8 \\
Treatment supporter & 256 & \\
Yes & 15 & 94.5 \\
No & & 5.5 \\
\hline
\end{tabular}

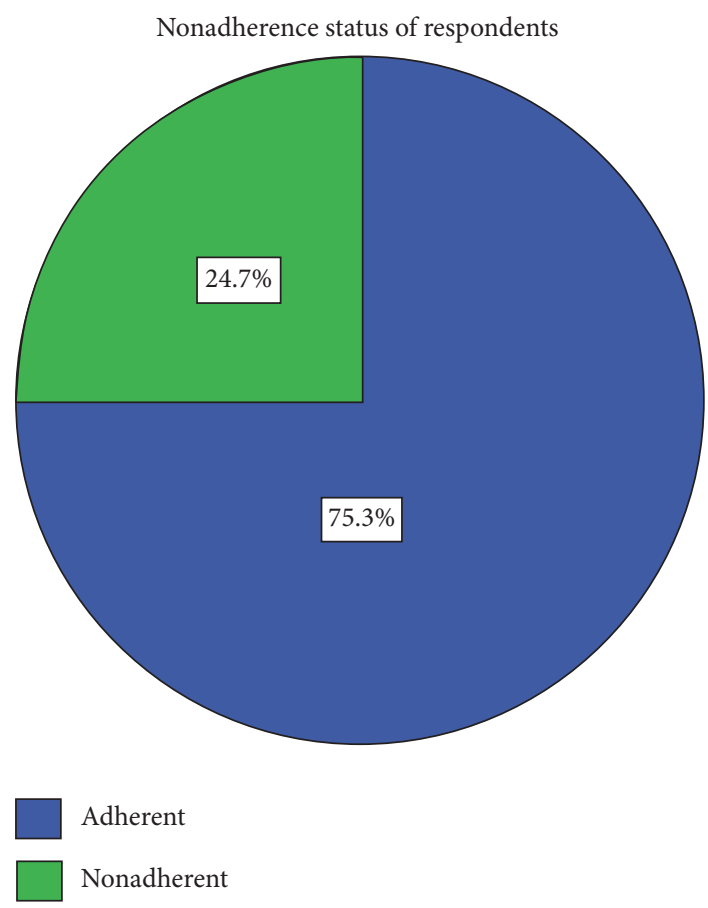

FIgURE 1: Adherence status of the TB patients that attended TB clinics at governmental health institutions of Arba Minch town, Southern Ethiopia, $2017(N=271)$.

3.6. Factors Associated with Nonadherence to Anti-TB Treatment. In bivariate analysis, sex, educational status, waiting time at health facility, distance to health facility, side effects of the drugs, smoking, alcohol use, treatment supporter, and monthly income were significantly associated with nonadherence to anti-TB medication. But in multivariate analysis, patients who experienced drug side effects, those who were far from the health facility, and those that experienced a prolonged waiting time to get medical services remained significantly and independently associated with anti-TB medication nonadherence. Those patients that experienced side effects were thirteen times more likely (AOR $=13.332 ; 95 \%$ CI: 2.282-77.905) to be nonadherent than their counterparts. In addition, patients that came from a far distance to the health facility to get medical services $(\mathrm{AOR}=21.830 ; 95 \%$
TABLE 3: Healthcare system related characteristics of the TB patients that attended TB clinics at governmental health institutions of Arba Minch town, Southern Ethiopia, $2017(N=271)$.

\begin{tabular}{|c|c|c|}
\hline Variable & Frequency & Percent \\
\hline \multicolumn{3}{|l|}{ Preferable time for TB clinic } \\
\hline 2:00-6:00 AM & 150 & 55.3 \\
\hline 8:00-11:00 AM & 120 & 44.3 \\
\hline After 2 PM & 1 & 0.4 \\
\hline \multicolumn{3}{|l|}{ Waiting time at health facility } \\
\hline$<1 \mathrm{hr}$ & 225 & 83.0 \\
\hline $1-2 \mathrm{hr}$ & 46 & 17.0 \\
\hline \multicolumn{3}{|l|}{ Distance to health facility } \\
\hline $0-5 \mathrm{~km}$ & 215 & 79.3 \\
\hline$>5 \mathrm{~km}$ & 56 & 20.7 \\
\hline \multicolumn{3}{|l|}{ Transport cost } \\
\hline $0-5$ birr & 215 & 79.3 \\
\hline$>5$ birr & 56 & 20.7 \\
\hline \multicolumn{3}{|l|}{ Supervision } \\
\hline None & 44 & 16.2 \\
\hline Family member & 17 & 6.3 \\
\hline Health worker & 210 & 77.5 \\
\hline \multicolumn{3}{|l|}{ Relationship with health worker } \\
\hline Very friendly & 22 & 8.1 \\
\hline Friendly & 208 & 76.8 \\
\hline Indifferent & 32 & 11.8 \\
\hline Unfriendly & 9 & 3.3 \\
\hline \multicolumn{3}{|l|}{ Knowledge on symptoms of TB } \\
\hline All & 144 & 53.2 \\
\hline Some & 115 & 42.4 \\
\hline Not knowing & 12 & 4.4 \\
\hline \multicolumn{3}{|l|}{ Time to stop TB medication } \\
\hline $6-24$ months & 132 & 48.7 \\
\hline $8-24$ months & 93 & 34.3 \\
\hline When feeling better & 46 & 17.0 \\
\hline \multicolumn{3}{|l|}{ TB status disclosure } \\
\hline Yes & 249 & 91.9 \\
\hline No & 22 & 8.1 \\
\hline \multicolumn{3}{|l|}{ Reason for not disclosing } \\
\hline Fear of stigma and discrimination & 22 & 100 \\
\hline
\end{tabular}

CI: 0.0-554-77.500) and those who experienced a prolonged waiting time at the health facility to get medical services (AOR $=14.260 ; 95 \%$ CI: 2.135-95.241) were also at a higher risk of nonadherence than those who were near the health facility and those that waited for a short period of time, respectively (Table 5).

\section{Discussion}

This study assessed anti-TB drug nonadherence and the associated factors among TB patients in Arba Minch governmental health institutions. Even if it is recommended that every TB patient should adhere to anti-TB medication by following DOT strategy [1], the findings of this study showed 
TABLE 4: Disease and medicine related characteristics of the TB patients that attended TB clinics at governmental health institutions of Arba Minch town, Southern Ethiopia, $2017(N=271)$.

\begin{tabular}{|c|c|c|}
\hline Variable & Frequency & Percent \\
\hline \multicolumn{3}{|l|}{ Experience of side effects } \\
\hline Yes & 30 & 11.1 \\
\hline No & 241 & 88.9 \\
\hline \multicolumn{3}{|l|}{ Type of side effects } \\
\hline Vomiting and diarrhea & 10 & 33.4 \\
\hline Headache and dizziness & 7 & 23.4 \\
\hline Skin rash & 4 & 13.3 \\
\hline Numbness of feet and hands & 9 & 30 \\
\hline \multicolumn{3}{|l|}{ Duration to feel better } \\
\hline$<2$ months & 257 & 94.8 \\
\hline $2-4$ months & 9 & 3.3 \\
\hline 5-6 months & 5 & 1.8 \\
\hline \multicolumn{3}{|l|}{ Missing of anti-TB medication } \\
\hline Yes & 69 & 25.5 \\
\hline No & 202 & 74.5 \\
\hline \multicolumn{3}{|c|}{ Reason for missing anti-TB medication } \\
\hline Forgetfulness & 15 & 21.7 \\
\hline Vomiting and diarrhea & 4 & 5.9 \\
\hline Cost of transport & 5 & 7.2 \\
\hline Health professional attitude & 3 & 4.3 \\
\hline Stigma and discrimination & 7 & 10.1 \\
\hline Feeling better & 35 & 50.8 \\
\hline \multicolumn{3}{|l|}{ HIV status } \\
\hline Positive & 6 & 2.2 \\
\hline Negative & 223 & 82.3 \\
\hline Not tested & 42 & 15.5 \\
\hline \multicolumn{3}{|c|}{ Taking drugs other than anti-Tb medication } \\
\hline Yes & 14 & 5.2 \\
\hline No & 257 & 94.8 \\
\hline \multicolumn{3}{|l|}{ Reason of taking another drug } \\
\hline HIV/AIDS & 6 & 42.8 \\
\hline Pneumonia & 2 & 14.3 \\
\hline STI & 1 & 7.1 \\
\hline Fungal disease & 5 & 35.8 \\
\hline
\end{tabular}

that $24.7 \%$ of TB patients did not adhere to anti-TB drugs. This finding is almost in line with the finding of the study conducted in a tertiary health institution in Southeast Nigeria and in South Ethiopia where nonadherence for anti-TB drugs was $24.2 \%$ and $24.5 \%$, respectively [21, 22]. In this study, the proportion of TB patients that do not adhere to antiTB drugs is higher compared to the findings of the study conducted in Southwest Ethiopia and Northwest Ethiopia where the nonadherence was $20.8 \%$ and $10 \%$, respectively $[20,23]$. This discrepancy could be, in the first case, because the study was conducted in three big towns in North Ethiopia and, in the second case, could be because the study finding only represents the result from a single hospital and only few patients. In the current study, the number of TB patients that did not adhere to anti-TB drugs is relatively smaller than that found by a study conducted in Hadiya Zone, Southern Ethiopia, where nonadherence was 30\% [24]. This might be attributable to the fact that the finding of the study conducted in Hadiya Zone represents TB patients both in higher health facilities and in rural health facilities, whereas our study was only restricted to patients from health facilities located in an urban setting, which is Arba Minch town.

In this study, one reason for nonadherence of anti-TB drugs is the waiting time at the health facility. While only $10.2 \%$ of TB patients waiting for less than 1 hour did not adhere to anti-TB drugs, $95.7 \%$ of TB patients waiting for 12 hours did not adhere. This is similar to the finding of the study conducted in Hadiya Zone, Southern Ethiopia, where the probability of complying with DOT is 2.5 times higher for TB patients waiting for less than 30 minutes compared to their counterparts [24].

The other important reason for anti-TB nonadherence among TB patients is distance to the health facility. While only $8.4 \%$ of TB patients $0-5 \mathrm{kms}$ away from health facility did not adhere to anti-TB drugs, $87.5 \%$ of TB patients greater than $5 \mathrm{kms}$ away from the health facility did not adhere. Similarly, the study conducted in South Ethiopia has depicted that the likelihood of not adhering to anti-TB drugs for TB patients faraway from DOT center is 5.7 times higher than TB patients nearer to the center [22].

Side effects of the drugs are also an important reason for anti-TB drug nonadherence among TB patients. While the likelihood of not adhering to anti-TB drugs among TB patients with side effects of the drugs is $90 \%$, only $16.6 \%$ of TB patients without the side effects of the drugs did not adhere to anti-TB drugs. This finding is in line with the finding of the study carried out in Tigray, Northern Ethiopia, where the probability of adhering to anti-TB drugs among TB patients without drugs side effects was 3 times higher than in those with drugs side effects [25]. Similarly, in a study carried out in Alamata District, Northeast Ethiopia, one of the main reasons for nonadherence was the presence of drugs side effects among TB patients [26].

In this study, some variables which were significant during bivariate analysis were not found to be statistically significant during multivariate analysis and were not independent determinants of anti-TB drug nonadherence among TB patients. One of such variables was sex, which in this study has no effect on anti-TB drug nonadherence among TB patients. Similarly, studies conducted in Southeast Nigeria and Plateau State, Nigeria, have shown that sex has no significant effect on anti-TB drug nonadherence among TB patients $[21,27]$. On the contrary, the study conducted in Argentina has shown that difference in sex has an effect on anti-TB drug nonadherence among TB patients [28]. The other variable with no effect on anti-TB drug nonadherence in this study was educational status. In the same manner, studies carried out in South Ethiopia and Plateau State, Nigeria, have indicated that the educational status of TB patients has no effect on anti-TB drug nonadherence [22, 27]. But studies conducted in Southwest Ethiopia and Southeast Nigeria have shown that educational status has a significant effect on anti-TB drug nonadherence among TB patients $[20,21]$. Similarly, having a treatment supporter in this study 
TABLE 5: Factors associated with nonadherence of anti-TB drug treatment among TB patients that attended TB clinics at governmental health institutions of Arba Minch town, Southern Ethiopia $(N=271)$.

\begin{tabular}{|c|c|c|c|c|}
\hline \multirow{2}{*}{ Variables } & \multicolumn{2}{|c|}{ Nonadherence } & \multirow{2}{*}{ Crude OR } & \multirow{2}{*}{ Adjusted OR } \\
\hline & Yes & No & & \\
\hline \multicolumn{5}{|l|}{ Sex } \\
\hline Male & $50(31.6 \%)$ & $108(68.4 \%)$ & 1 & 1 \\
\hline Female & $17(15.0 \%)$ & $96(85.0 \%)$ & $0.383(0.207,0.708)$ & $3.023(0.071,11.335)$ \\
\hline \multicolumn{5}{|l|}{ Educational status } \\
\hline Cannot read and write & $15(60.0 \%)$ & $10(40.0 \%)$ & $5.250(1.566,17.601)$ & $1.923(0.023,8.013)$ \\
\hline Can read and write & $13(21.0 \%)$ & $49(79.0 \%)$ & $0.929(0.311,2.773)$ & $0.745(0.154,3.257)$ \\
\hline Grades 1-6 & $19(25.3 \%)$ & $56(74.7 \%)$ & $1.187(0.417,3.380)$ & $0.247(0.099,6.227)$ \\
\hline Grades 7-12 & $14(17.1 \%)$ & $68(82.9 \%)$ & $0.721(0.246,2.110)$ & $2.016(0.085,11.663)$ \\
\hline Diploma and above & $6(22.2 \%)$ & $21(77.8 \%)$ & 1 & 1 \\
\hline \multicolumn{5}{|c|}{ Waiting time at health facility } \\
\hline$<1$ hour & $23(10.2 \%)$ & $202(89.8 \%)$ & 1 & 1 \\
\hline 1-2 hours & $44(95.7 \%)$ & $2(4.3 \%)$ & $193.217(43.929,849.847)$ & $14.260(2.135,95.241)^{*}$ \\
\hline \multicolumn{5}{|l|}{ Distance to health facility } \\
\hline $0-5 \mathrm{~km}$ & $18(8.4 \%)$ & $197(91.6 \%)$ & 1 & 1 \\
\hline$>5 \mathrm{~km}$ & $49(87.5 \%)$ & $7(12.5 \%)$ & $76.611(30.306,193.669)$ & $21.830(5.278,90.284)^{*}$ \\
\hline \multicolumn{5}{|l|}{ Side effects of the drugs } \\
\hline Yes & $27(90 \%)$ & $3(10 \%)$ & $45.000(13.020,155.528)$ & $13.332(2.282,77.905)^{*}$ \\
\hline No & $40(16.6 \%)$ & $201(83.4 \%)$ & 1 & 1 \\
\hline \multicolumn{5}{|l|}{ Smoking } \\
\hline Yes & $20(90.9 \%)$ & $2(9.1 \%)$ & $42.979(9.708,190.282)$ & $0.903(0.080,10.200)$ \\
\hline No & $47(18.9 \%)$ & $202(81.1 \%)$ & 1 & 1 \\
\hline \multicolumn{5}{|l|}{ Alcohol } \\
\hline Yes & $43(97.7 \%)$ & $1(2.3 \%)$ & $363.708(47.899,2761.726)$ & $2.665(0.897,9.776)$ \\
\hline No & $24(10.6 \%)$ & $203(89.4 \%)$ & 1 & 1 \\
\hline \multicolumn{5}{|l|}{ Treatment supporter } \\
\hline Yes & $53(20.7 \%)$ & $203(79.3 \%)$ & 1 & 1 \\
\hline No & $14(93.3 \%)$ & $1(6.7 \%)$ & $53.623(6.895,417.018)$ & $2.044(0.054,77.500)$ \\
\hline \multicolumn{5}{|l|}{ Monthly income } \\
\hline$<501$ birr & $51(50 \%)$ & $51(50 \%)$ & $9.562(5.018,18.223)$ & $2.267(0.795,6.468)$ \\
\hline$>=501$ birr & $16(9.5 \%)$ & $153(90.5 \%)$ & 1 & 1 \\
\hline
\end{tabular}

${ }^{*}$ Significant association.

has no effect on anti-TB drug nonadherence, which is also in line with the finding of the study conducted in South Ethiopia [22]. The other variable that does not affect antiTB drug nonadherence status in this study was alcohol use. In the same way, studies carried out in South Ethiopia and Plateau State, Nigeria, have revealed that alcohol use has no significant effect on anti-TB drug nonadherence [22, 27]. Cigarette smoking was another variable in this study that does not affect anti-TB drug nonadherence status, but the study conducted in Plateau State, Nigeria, has shown that cigarette smoking is significantly associated with anti-TB drug nonadherence among TB patients [27]. The last variable that is not associated with anti-TB drug adherence status among TB patients in this study was monthly income of TB patients, which is contrary to the finding of the study carried out in Southeast Nigeria where the average monthly income has significantly affected anti-TB drug adherence status of TB patients [21].

\section{Conclusions}

In general, this study revealed that the level of nonadherence to anti-TB drugs among TB patients in Arba Minch governmental health institutions is high. The waiting time at the health facility, the distance to the health facility, and the side effects of the drugs were significant determinants of nonadherence to anti-TB drugs. The other variables such as sex, educational status, smoking, alcohol use, treatment supporter, and monthly income were only significantly associated with nonadherence to anti-TB medication during bivariate analysis. And they were not found to be statistically significant during multivariate analysis.

\section{Conflicts of Interest}

The authors declare that there are no conflicts of interest regarding the publication of this paper. 


\section{Acknowledgments}

The authors' sincere thanks go to Arba Minch University for provision of the opportunity to conduct the research. They would also like to give their deepest gratitude to Gamo Gofa Zone Health Department for providing baseline information. Lastly, their thanks go to data collectors and all research participants who took part in the study.

\section{References}

[1] WHO, WHO Global Tuberculosis Report 2016, WHO Press, Geneva, Switzerland, 2016.

[2] A. C. Lemos, E. D. Matos, D. B. Pedral-Sampaio, and E. M. Netto, "Risk of tuberculosis among household contacts in Salvador, Bahia," The Brazilian Journal of Infectious Diseases, vol. 8, no. 6, pp. 424-430, 2004.

[3] J. A. Caminero, "A tuberculosis guide for specialist physicians," International Union Against Tuberculosis and Lung Diseases, vol. 24, 2003.

[4] WHO, The Global Plan to Stop TB 2006-2015, World Health Organization, Geneva, Switzerland, 2006.

[5] L. H. Rieder, "Interventions for tuberculosis control and elimination," Journal of International Union against Tuberculosis and Lung Diseases, vol. 5, 2002.

[6] E. Sabate, Adherence to Long-Term Therapies: Evidence for Action, WHO, Geneva, Switzerland, 2003.

[7] A. Harries, D. Maher, and S. Graham, TB/HIV: A Clinical Manual, World Health Organization, Geneva, Switzerland, 2004.

[8] N. Awofeso, "Anti tuberculosis medication side-effects constitute major factor for poor adherence to tuberculosis treatment," Bulletin of the World Health Organization, vol. 86, no. 3, 2008.

[9] WHO, WHO report 2011/Global Tuberculosis Control, WHO, France, Europe, 2011.

[10] Ethiopia FMoH Tuberculosis, Leprosy and TB/HIV Prevention and Control Programme. Addis Ababa, Ethiopia 207 p, 2008.

[11] Ch. Kudakwashe, "Factor affecting compliance to tuberculosis treatment in Andra Kanvango region in Namibia," Journal of compliance to TB treatment, pp. 5-6, 2010.

[12] WHO, Global Tuberculosis Control: Surveillance, Planning, Financing, WHO Press, Geneva, Switzerland, 2008.

[13] Z. Obermeyer, J. Abbott-Klafter, and C. J. L. Murray, "Has the DOTS strategy improved case finding or treatment success? an empirical assessment," PLoS ONE, vol. 3, no. 3, Article ID el721, 2008.

[14] X. Yin, X. Tu, Y. Tong, R. Yang, Y. Wang, S. Cao et al., "Development and validation of a tuberculosis medication adherence scale," PLoS ONE, vol. 7, no. 12, Article ID e50328, 2012.

[15] WHO, Global Tuberculosis Control Report of 2011, WHO Press, Geneva, Switzerland, 2012.

[16] H. H. Tola, A. Tol, D. Shojaeizadeh, and G. Garmaroudi, "Tuberculosis treatment non -adherence and lost to Follow up among TB patients with or without HIV in Developing countries: a systematic review," Iranian Journal of Public Health, vol. 44, no. 1, pp. 1-11, 2015.

[17] P. Charles, "Felton national tuberculosis center. adherence to treatment for latent tuberculosis infection," A Manual for Health Care Providers, 2005.
[18] M. F. Franke, S. C. Appleton, F. Arteaga et al., "Risk factors and mortality associated with default from multidrug-resistant tuberculosis treatment," Clinical Infectious Diseases, vol. 48, no. 12, pp. 1844-1851, 2008.

[19] B. Castelnuovo, "A review of compliance to anti tuberculosis treatment and risk factors for defaulting treatment in Sub Saharan Africa," African Health Sciences, vol. 10, no. 4, pp. 320324, 2010.

[20] A. Kebede and N. T. Wabe, "Medication adherence and its determinants among patients on concomitant tuberculosis and antiretroviral therapy in South West Ethiopia," North American Journal of Medical Sciences, vol. 4, no. 2, pp. 67-71, 2012.

[21] C. F. Ubajaka, E. C. Azuike, J. O. Ugoji et al., "Adherence to drug medications amongst tuberculosis patients in a tertiary health institution in South East Nigeria," International Journal of Clinical Medicine, vol. 06, no. 06, pp. 399-406, 2015.

[22] T. T. Woimo, W. K. Yimer, T. Bati, and H. A. Gesesew, "The prevalence and factors associated for anti-tuberculosis treatment non-adherence among pulmonary tuberculosis patients in public health care facilities in South Ethiopia: a crosssectional study," BMC Public Health, vol. 17, no. 1, article no. 269, 2017.

[23] A. A. Adane, K. A. Alene, D. N. Koye, and B. M. Zeleke, "Nonadherence to anti-tuberculosis treatment and determinant factors among patients with tuberculosis in Northwest Ethiopia," PLoS ONE, vol. 8, no. 11, Article ID e78791, 2013.

[24] B. Bayu, A. Lonsako, and L. Tegene, "Directly observed treatment short-course compliance and associated factors among adult tuberculosis cases in public health institutions of Hadiya zone, Southern Ethiopia," Journal of Infectious Diseases and Immunity, vol. 8, no. 1, pp. 1-9, 2016.

[25] Y. K. Kiros, T. Teklu, F. Desalegn, M. Tesfay, E. Klinkenberg, and A. Mulugeta, "Adherence to anti-tuberculosis treatment in Tigray, Northern Ethiopia," Public Health Action, vol. 4, no. 4, pp. 531-536, 2014.

[26] G. Tesfahuneygn, G. Medhin, and M. Legesse, "Adherence to anti-tuberculosis treatment and treatment outcomes among tuberculosis patients in Alamata District, Northeast Ethiopia," BMC Research Notes, vol. 8, no. 503, 2015.

[27] L. M. Ibrahim, I. S. Hadejia, P. Nguku et al., "Factors associated with interruption of treatment among Pulmonary Tuberculosis patients in Plateau State, Nigeria. 2011," Pan African Medical Journal, vol. 17, no. 78, 2014.

[28] M. B. Herrero, S. Ramos, and S. Arrossi, "Determinants of non adherence to tuberculosis treatment in argentina: Barriers related to access to treatment," Revista Brasileira de Epidemiologia, vol. 18, no. 2, pp. 287-298, 2015. 


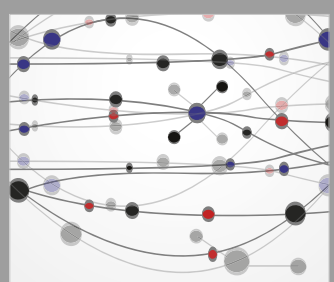

The Scientific World Journal
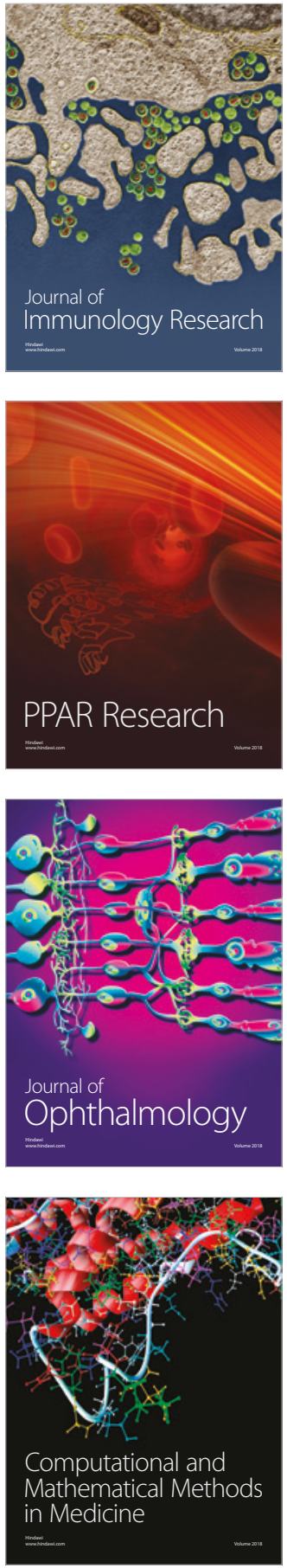

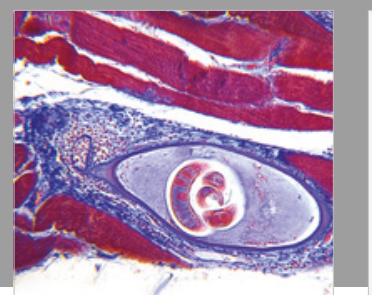

Gastroenterology Research and Practice

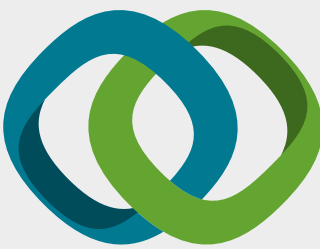

\section{Hindawi}

Submit your manuscripts at

www.hindawi.com
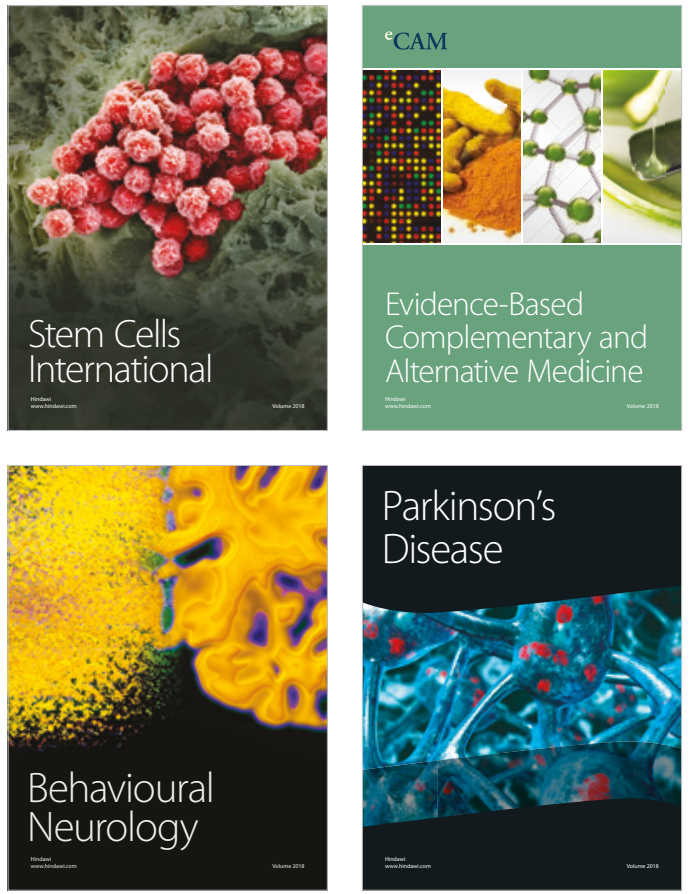

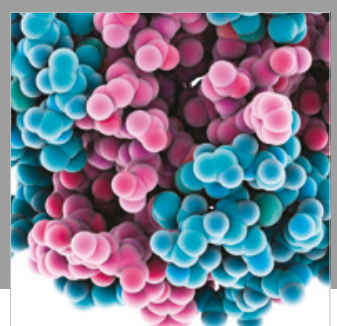

ournal of

Diabetes Research

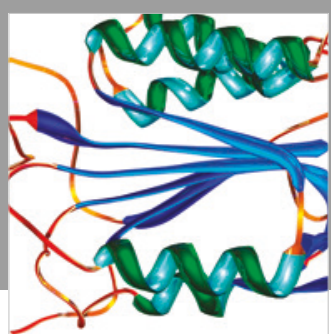

Disease Markers
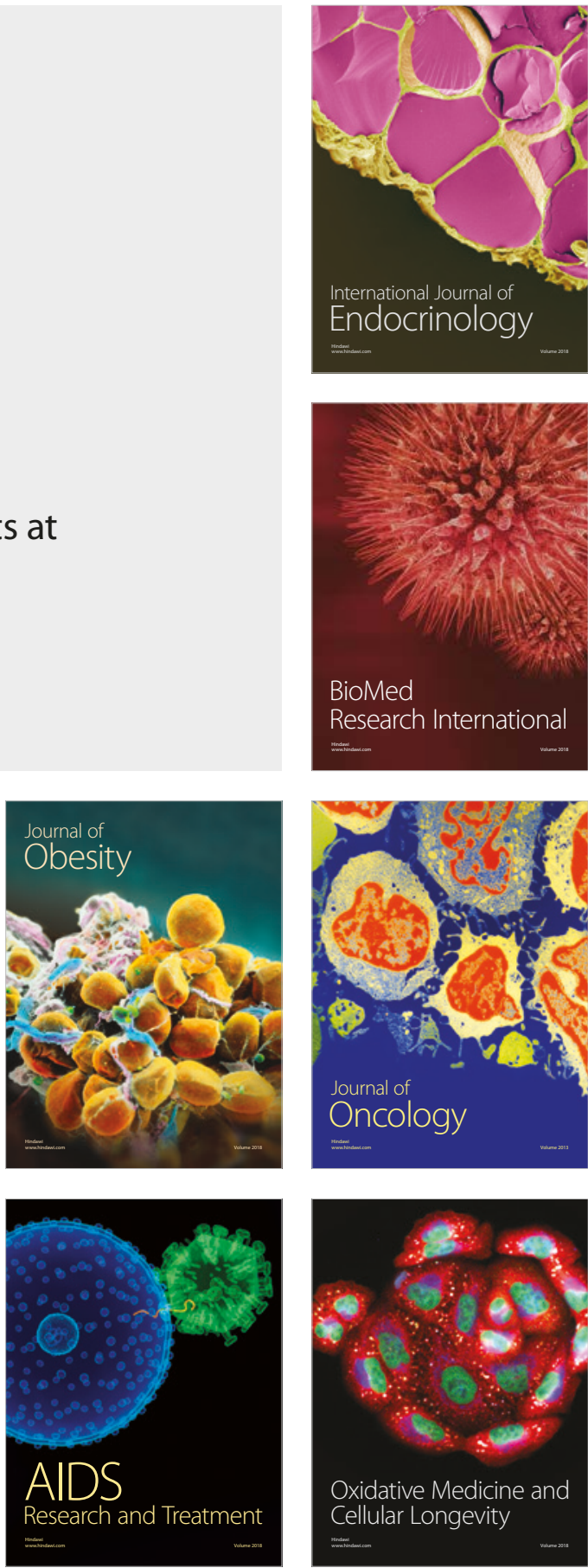